\title{
Dislodged Levornogestrel-Intrauterine System Intra-Abdominally without Uterine Perforation: Is it Possible?
}

\author{
$\operatorname{Ng} \mathrm{BK}^{1}(\bowtie), \operatorname{Lim} \mathrm{PS}^{1}$, Shahizon $\mathrm{AMM}^{2}, \mathrm{Ng} \mathrm{YL}^{2}$, Shafiee $\mathrm{MN}^{1}$, Omar $\mathrm{MH}^{1}$ \\ ${ }^{1}$ Department of Obstetrics and Gynaecology, ${ }^{2}$ Department of Radiology, Faculty of Medicine, Universiti \\ Kebangsaan Malaysia Medical Centre, Jalan Yaacob Latif, Bandar Tun Razak, 56000 Cheras, Kuala \\ Lumpur, Malaysia.
}

\begin{abstract}
We report a case of dislodged Levornogestrel-intrauterine system (LNG-IUS, Mirena ${ }^{\circledR}$ ) without evidence of uterine perforation. A 37-year-old Para 4+1presented with 3 months history of lower abdominal pain. Examination and imaging showed that the device was not present in the uterine cavity. She underwent laparoscopic retrieval of Mirena ${ }^{\circledR}$. There was no evidence of uterine perforation intra-operatively. This case illustrated the rare possibility of dislodged Mirena ${ }^{\circledR i n t r a-a b d o m i n a l l y ~ w i t h o u t ~ e v i d e n c e ~ o f ~ u t e r i n e ~ p e r f o r a t i o n . ~ T h e ~ m a n a g e m e n t ~ f o r ~ m i s s i n g ~ I U S ~ w a s ~}$ reviewed.
\end{abstract}

Keywords: abdominal pain, contraception, laparoscopy, Levonogetsrel, uterine perforation

\section{Correspondence:}

Ng Beng Kwang, Department of Obstetrics and Gynaecology, Faculty of Medicine, Universiti Kebangsaan Malaysia Medical Centre, Jalan Yaacob Latif, Bandar Tun Razak, 56000 Cheras, Kuala Lumpur, Malaysia. Tel: +603-91455949 Fax: +60391456672 Email: nbk_9955@yahoo.com,nbk9955@ppukm.ukm.edu.my

\section{Introduction}

Levonorgestrel-intrauterine system (LNG-IUS, Mirena ${ }^{\circledR}$ ) was one of the most commonly used longacting reversible contraception. Its usage ranges widely from $2 \%$ to $80 \%$ in different countries (1), with $83 \%$ of world users from Asia region (2). Mirena ${ }^{\circledR}$ being an effective contraception with reported Pearl Index of 0.15 and 0.22 through year 1 and 3 respectively (3), had been recognised as an optimal treatment option for heavy menstrual bleeding and dysmenorrhea (1). However, the usage of Mirena ${ }^{\circledR}$ was not without its side effect or complication. We reported a case of dislodged Mirena ${ }^{\circledR}$ intraabdominally without evidence of uterine perforation and reviewed the option of management.

\section{Case Report}

A 37-year-old Para 4+1, presented to our centre with history of intermittent lower abdominal pain for the past 3 months requesting for Mirena ${ }^{\circledR}$ removal. She had Mirena ${ }^{\circledR}$ inserted in August 2014, 6 weeks post partum, by her family physician as contraception. She used the same contraceptive method prior to her last pregnancy. Soon after Mirena ${ }^{\circledR}$ insertion, she experienced some cramping abdominal discomfort, which was relieved by simple oral analgesia. Presence of Mirena ${ }^{\circledR}$ thread was confirmed for the first 3 months as she had regular self-checking. Subsequently, she started experiencing irregular and prolonged vaginal bleeding with lower abdominal pain. She had no significant medical history. Her first delivery was via emergency lower segment caesarean section for poor progress, followed by complete miscarriage and 2 full term assisted vaginal deliveries. During speculum examination, Mirena ${ }^{\circledR}$ thread was not seen. Pelvic ultrasound revealed empty uterus with no evidence of Mirena ${ }^{\circledR}$ present in the uterine cavity. Computed tomography (CT) scan showed that the contraceptive device was located at the right pelvic cavity (Fig. 1). Diagnostic laparoscopy was performed 


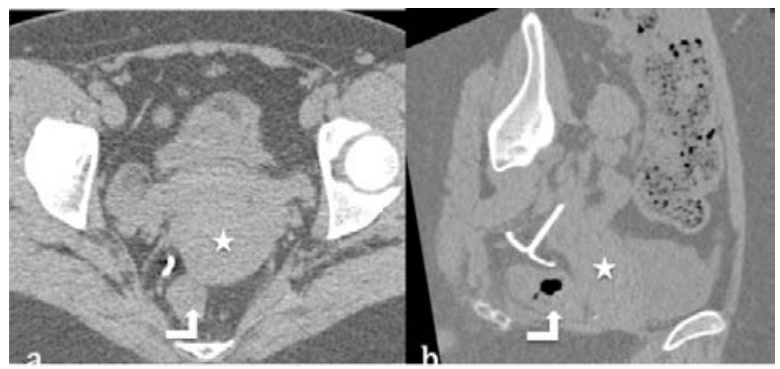

Figure 1: Non-enhanced CT scan of the pelvis in axial (a) and reformatted sagittal oblique (b). The $\mathrm{T}$ shape IUD is completely extra-uterine located anterolateral to the rectum (bent arrow) and postero-lateral to the uterus (star). The uterine outline is normal.

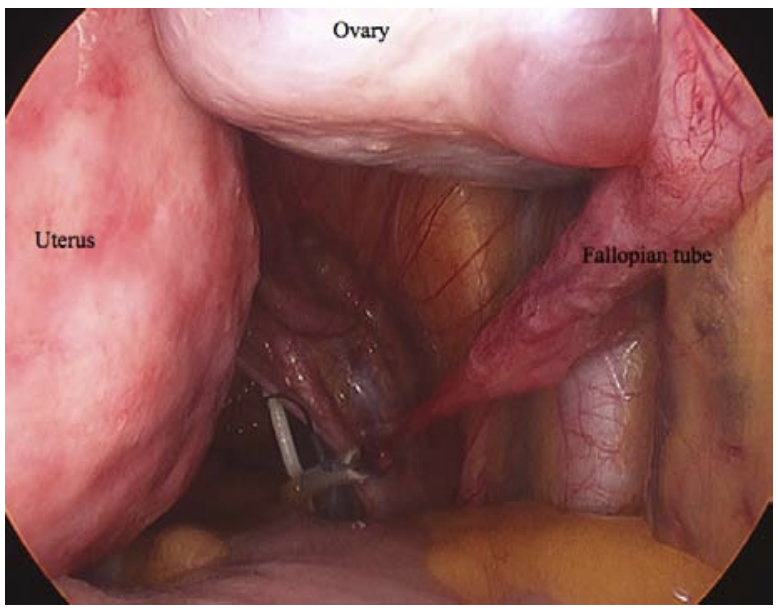

Figure 2: Laparoscopy showed presence of LNG-IUS attached to the fimbriae end of right fallopian tube.

performed. The device was found attached to the fimbriae end of right fallopian tube without any significant pelvic adhesion or evidence of uterine perforation (Fig. 2). She had an uneventful laparoscopic retrieval of the Mirena ${ }^{\circledR}$.

\section{Discussion}

Continuous abdominal discomfort and irregular vaginal bleeding are the main reason for discontinuation of Mirena ${ }^{\circledR}$ use (4). The patient had lower abdominal discomfort and irregular vaginal bleeding for months after Mirena ${ }^{\circledR}$ insertion. She assumed those were side effects of Mirena ${ }^{\circledR}$ without any suspicious of her Mirena ${ }^{\circledR}$ being dislodged. Thus, she did not seek any treatment until her symptoms became unbearable and she requested for removal of Mirena ${ }^{\circledR}$.

A rare complication of Mirena ${ }^{\circledR}$ insertion was uterine perforation. The incidence of such complication ranged from 1.4-2.6 per 1000 insertion $(5,6)$.
Unfortunately, only $8.5 \%$ of the perforations were diagnosed at the time of insertion (7). Majority of patients (73\%) were symptomatic with mild abdominal pain or abnormal vaginal bleeding (8). Asymptomatic patients were diagnosed mainly because of missing IUD threads or unintended pregnancy. Up to $75 \%$ of patients had onset of symptoms within 24 hours of insertion (8). As the side effects of Mirena ${ }^{\circledR}$ were similar to presentation of uterine perforation, thus the mean time taken from insertion to establishing the diagnosis was around 5 months (0-69 months) (8).

Various imaging techniques had been used to locate the missing IUS with vaginal ultrasound being the most widely used modality. Other imaging includes abdominal radiography, hysteroscopy and CT scan $(8,9)$. Besides that, Banerjee et al. described the use of fluoroscopy to help in localising the missing device when ultrasound, abdominal radiography and diagnostic laparoscopy failed to locate it (10). This patient had trans-vaginal ultrasound, which revealed absence of the device within the uterine cavity. CT scan was eventually performed and managed to locate the missing contraceptive device, which was situated in close proximity to the right fallopian tube. Unusual consequences after uterine perforation such as migration of Mirena ${ }^{\circledR}$ to the bladder (11) and small bowel obstruction (12) had been reported in the literature. Hence, imaging modalities are important pre-operative assessment tools that could assist in the planning of surgical retrieval.

Majority of patients with missing IUS were managed surgically i.e. via laparoscopic route (8). Most of these missing devices were embedded within the omentum $(65 \%)$ or within the pelvic cavity (35\%). Surgical findings were usually unremarkable, as majority of these patients had no intra-abdominal adhesion (8). The patient had an uneventful laparoscopic retrieval of the missing IUS as there was only minimal adhesion noted between the device and the fimbrial end of right fallopian tube. Not surprisingly, there was no evidence of uterine perforation intra-operatively as the patient still managed to feel the thread 3 months after insertion. This raises the question: can Mirena ${ }^{\circledR}$ migrate through the fallopian tube to the abdominal cavity without uterine perforation? To date, there is no published report in the literature. Hence, this assumption is disputable.

On the other hand, conservative management without surgical removal had also been reported in literature without much complication. Budiman et al. reported a 39-year-old woman who became pregnant while on Mirena ${ }^{\circledR}$. Caesarean section performed later found that the missing device was within the omentum (13). 
Furthermore, Hopkins et al described a 6\% risk of congenital anomalies in 35 pregnancies while using Mirena ${ }^{\circledR}$; whereby 34 of these pregnancies were with intrauterine LNG-IUS and one with intraperitoneal LNG-IUS (14). Hence, conservative management could be an alternative option in selected cases.

\section{Conclusion}

It was crucial to be always on the lookout for possibility of complication even with simple procedures such as insertion of Mirena ${ }^{\circledR}$. Thorough assessment and localisation of the missing intrauterine device with the help of imaging modalities are of paramount importance before any surgical intervention in order to minimise further morbidity and litigation.

\section{References}

1. ESHRE Capri Workshop Group. Intrauterine devices and intrauterine systems. Hum Reprod Update 2008; 14(3): 197-208.

2. Buhling KJ, Zite NB, Lotke P, Black K. Worldwide use of intrauterine contraception: a review. Contraception 2014; 89(3): 162-73.

3. Eisenberg DL, Schreiber CA, Turok DK, Teal SB, Westhoff CL, Creinin MD. Three-year efficacy and safety of a new 52-mg levonorgestrel-releasing intrauterine system. Contraception 2015; 92(1): 10-6.

4. Backman T. Benefit-risk assessment of the levornogestrel intrauterine system in contraception. Drug Saf 2004; 27(15): 1185-204.

5. Heinemann K, Reed S, Moehner S, Minh TD. Risk of uterine perforation with levonorgestrelreleasing and copper intrauterine devices in the European Active Surveillance Study on Intrauterine Devices. Contraception 2015; 91(4): 274-9.

6. Van Houdenhoven $\mathrm{K}$, van Kaam KJ, van Grootheest AC, Salemans TH, Dunselman GA. Uterine perforation in women using a levonorgestrel-releasing intrauterine system. Contraception 2006; 73(3): 257-60.

7. Van Grootheest K, Sachs B, Harrison-Woolrych M, Caduff-Janosa P, van Puijenbroek E. Uterine perforation with the levonorgestrel-releasing intrauterine device: analysis of reports from four national pharmacovigilance centres. Drug Saf 2011; 34(1): 83-8.

8. Kaislasuo J, Suhonen S, Gissler M, Lahteenmaki $\mathrm{P}$, Heikinheimo O. Uterine perforation caused by intrauterine devices: clinical course and treatment. Hum Reprod 2013; 28(6): 1546-51.

9. Mahmoud MS, Merhi ZO. Computed tomography-assisted laparoscopic removal of intraabdominally migrated levonorgestrelreleasing intrauterine systems. Arch Gynecol Obstet 2010; 281(4): 627-30.

10. Banerjee J, Jeelani R, Berman JM, Diamond MP. Missing IUD and utilization of fluoroscopy for management: a case report. Contraception 2012; 86(3): 285-7.

11. Khan ZA, Khan SA, Williams A, Mobb GE. Intravesical migration of levonorgestrel-releasing intrauterine system (LNG-IUS) with calculus formation. Eur J Contracept Reprod Health Care 2006; 11(3): 243-5.

12. Loveless A, Dhari A, Klipatrick CC. Perforated levonorgestrel-releasing intrauterine system resulting in small bowel obstruction: a case report. J Reprod Med 2014; 59(11-12): 611-3.

13. Budiman H, Kumper C, Mylonas I, Thaler CJ, Friese K, Weissenbacher ER. Pregnancy in a patient with a displaced levonorgestrel-releasing intrauterine system: a case report. Arch Gynecol Obstet 2007; 276(3): 263-4.

14. Hopkins MR, Agudelo-Suarez P, El-Nashar SA, Creedon DJ, Rose CH, Famuyide AO. Term pregnancy with intraperitoneal levonorgestrel intrauterine system: a case report and review of the literature. Contraception 2009; 79(4): 323-7. 